\title{
Author Correction: Prioritizing multiple therapeutic targets in parallel using automated DNA-encoded library screening
}

Carl A. Machutta, Christopher S. Kollmann, Kenneth E. Lind, Xiaopeng Bai, Pan F. Chan, Jianzhong Huang, Lluis Ballell, Svetlana Belyanskaya, Gurdyal S. Besra, David Barros-Aguirre, Robert H. Bates, Paolo A. Centrella, Sandy S. Chang, Jing Chai, Anthony E. Choudhry, Aaron Coffin, Christopher P. Davie, Hongfeng Deng, Jianghe Deng, Yun Ding, Jason W. Dodson, David T. Fosbenner, Enoch N. Gao, Taylor L. Graham, Todd L. Graybill, Karen Ingraham, Walter P. Johnson, Bryan W. King, Christopher R. Kwiatkowski, Joël Lelièvre, Yue Li, Xiaorong Liu, Quinn Lu, Ruth Lehr, Alfonso Mendoza-Losana, John Martin, Lynn McCloskey, Patti McCormick, Heather P. O'Keefe, Thomas O'Keeffe, Christina Pao, Christopher B. Phelps, Hongwei Qi, Keith Rafferty, Genaro S. Scavello, Matt S. Steiginga, Flora S. Sundersingh, Sharon M. Sweitzer, Lawrence M. Szewczuk, Amy Taylor, May Fern Toh, Juan Wang, Minghui Wang, Devan J. Wilkins, Bing Xia, Gang Yao, Jean Zhang, Jingye Zhou, Christine P. Donahue, Jeffrey A. Messer, David Holmes, Christopher C. Arico-Muendel, Andrew J. Pope, Jeffrey W. Gross \& Ghotas Evindar

Nature Communications 8:16081 doi: 10.1038/ncomms16081 (2017); Published 17 Jul 2017, Updated 13 Jul 2018

The original version of this Article omitted the following from the Acknowledgements:

'We thank Robert Kirkpatrick for implementing the high throughput protein design strategy that enabled screening and triage of essential A. baumannii targets, based on whole genome sequencing and annotation of BM4454 strain; and Stephanie Van Horn, Allan Kwan, Elizabeth Valoret for A. baumannii genome sequencing and annotation.'

Also, the original version omitted an acknowledgement to Prof. Lydia Tabernero as one of our collaborators for supplying the purified proteins used in the Tuberculosis screen.

This has been corrected in both the PDF and HTML versions of the Article.

\footnotetext{
(c) Open Access This article is licensed under a Creative Commons Attribution 4.0 International License, which permits use, sharing, adaptation, distribution and reproduction in any medium or format, as long as you give appropriate credit to the original author(s) and the source, provide a link to the Creative Commons

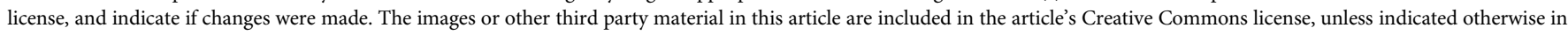

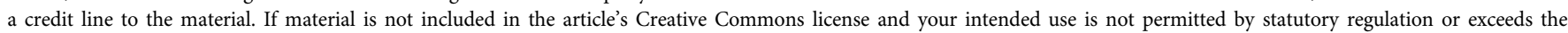
permitted use, you will need to obtain permission directly from the copyright holder. To view a copy of this license, visit http://creativecommons.org/licenses/by/4.0/

(C) The Author(s) 2018
} 